\title{
Surfactant Phosphatidylcholine Half-life and Pool Size Measurements in Premature Baboons Developing Bronchopulmonary Dysplasia
}

\author{
DAPHNE J.M.T. JANSSEN, VIRGILIO P. CARNIELLI, PAOLA E. COGO, STEVEN R. SEIDNER, \\ INGRID H.I. LUIJENDIJK, J.L. DARCOS WATTIMENA, ALAN H. JOBE, AND \\ LUC J.I. ZIMMERMANN \\ Department of Pediatrics/Neonatology, Sophia's Children's Hospital/Erasmus University Rotterdam, \\ Rotterdam, The Netherlands [D.J.M.T.J., I.H.I.L., L.J.I.Z.]; Institute of Child Health and Great Ormond \\ Street Hospital, University of London, London, U.K. [V.P.C.]; Department of Pediatrics/Neonatology, \\ University Hospital Padova, Padua, Italy [P.E.C.]; University of Texas Health Science Center, San \\ Antonio, Texas, U.S.A. [S.R.S.]; Department of Internal Medicine II, Erasmus University Rotterdam, \\ Rotterdam, The Netherlands [J.L.D.W.]; Pulmonary Biology, Children's Hospital Medical Center,
} Cincinnati, Ohio, U.S.A. [A.H.J.]

\begin{abstract}
ABST
Because minimal information is available about surfactant
metabolism in bronchopulmonary dysplasia, we measured half-
lives and pool sizes of surfactant phosphatidylcholine in very
preterm baboons recovering from respiratory distress syndrome
and developing bronchopulmonary dysplasia, using stable iso-
topes, radioactive isotopes, and direct pool size measurements.
Eight ventilated premature baboons received ${ }^{2} \mathrm{H}-\mathrm{DPPC}($ dipalmi-
toyl phosphatidylcholine) on d 5 of life, and radioactive ${ }^{14} \mathrm{C}-$
DPPC with a treatment dose of surfactant on $\mathrm{d} 8$. After $14 \mathrm{~d}$, lung
pool sizes of saturated phosphatidylcholine were measured. Half-
life of ${ }^{2} \mathrm{H}-\mathrm{DPPC}(\mathrm{d} 5)$ in tracheal aspirates was $28 \pm 4 \mathrm{~h}$ (mean
$\pm \mathrm{SEM}$ ). Half-life of radioactive DPPC (d 8 ) was $35 \pm 4 \mathrm{~h}$.
Saturated phosphatidylcholine pool size measured with stable
isotopes on d 5 was $129 \pm 14 \mu$ mol/kg, and $123 \pm 11 \mu \mathrm{mol} / \mathrm{kg}$
on d 14 at autopsy. Half-lives were comparable to those obtained
at d 0 and d 6 in our previous baboon studies. We conclude that
surfactant metabolism does not change during the early devel-
\end{abstract}
Since the introduction of surfactant therapy for the treatment of neonatal RDS, mortality and morbidity due to RDS have dramatically decreased (1). Most studies of surfactant metabolism have been performed in animals with radioactive tracers used to measure surfactant synthesis, half-life of surfactant, pool sizes, and influences of hormonal treatments $(2,3)$. Surfactant metabolism changes with lung injury and with devel-

Received February 13, 2002; accepted April 10, 2002.

Correspondence: Luc J. I. Zimmermann, M.D., Ph.D., Neonatology, Sophia's Children's Hospital, P.O. Box 2060, 3000 CB Rotterdam, The Netherlands; e-mail: Zimmermann@alkg.azr.nl

Supported by grants from the Sophia Foundation for Medical Research (SSWO 245), Rotterdam, The Netherlands, and the National Institute of Child Health, HL 52635 (The Southwest Foundation for Biomedical Research BPD Resource Center).

DOI: 10.1203/01.PDR.0000032072.27644.E4 opment of bronchopulmonary dysplasia, more specifically, the metabolism of exogenous surfactant on $\mathrm{d} 8$ is similar to that on the day of birth. Surfactant pool size is low at birth, increases after surfactant therapy, and is kept constant during the first $2 \mathrm{wk}$ of life by endogenous surfactant synthesis. Measurements with stable isotopes are comparable to measurements with radioactive tracers and measurements at autopsy. (Pediatr Res 52: 724-729, 2002)
Abbreviations
RDS, respiratory distress syndrome
BPD, bronchopulmonary dysplasia
GA, gestational age
DPPC, dipalmitoyl phosphatidylcholine
Sat PC, saturated phosphatidylcholine
PG, phosphatidylglycerol
Sp, sphingomyelin

opment. Newborn animals have less de novo synthesis and a longer biologic half-life of phosphatidylcholine (PC) than adult animals, but newborns also have higher rates of surfactant recycling (3). In adult animals, acute lung injury or oxygen exposure change surfactant composition and pool sizes (4).

Despite the progress in neonatal care, many very preterm infants develop BPD characterized by lung injury, inflammation, and an arrest in alveolar development (5). It is presently unclear whether the surfactant system is involved in the development of BPD. Most studies of surfactant metabolism in newborn animals and humans have been performed during the first days of life, during the acute phase of RDS. Almost no information is available about surfactant metabolism beyond the first week during the development of BPD (6). Infants who 
develop BPD have an altered phospholipid composition of surfactant $(7,8)$, and surfactant therapy in infants developing BPD resulted in a transient improvement of oxygenation (9). In ventilated preterm baboons developing BPD, the abnormal alveolar development and injury is similar to that found in humans (10). These very preterm baboons have a large increase in intracellular surfactant pool size during the first few days, but surfactant secretion to the alveolar space is very limited (11). Surfactant lipid and protein composition and surfactant function is abnormal in baboons developing BPD $(11,12)$. However, there is no information about the metabolism of the sat PC component of surfactant as the animals develop BPD.

We recently used stable isotopes to study the surfactant metabolism in premature human neonates $(13,14)$. However, a validation of the method using stable isotopes has not been performed because radioactive isotopes are medically and ethically not accepted in human newborns, and lung pool size of surfactant has only been measured in newborns who did not survive (15).

In the present study, we evaluated surfactant metabolism in very preterm ventilated baboons during the acute phase of RDS (d 1-3), the phase of recovery from RDS, and the development of BPD. We measured surfactant half-lives and pool sizes in each individual baboon during the first 2 wk of life. We were specifically interested in the changes of the surfactant metabolism in the second week of life during the development of BPD. Furthermore, we compared the surfactant half-life and surfactant pool size measured with stable isotopes to measurements made with radioactive isotopes and direct measurements of pool size at autopsy.

\section{METHODS}

Study protocol. The animal studies were performed at the Southwest Foundation for Biomedical Research (San Antonio, TX, U.S.A.), as described before and conformed to the American Association for Accreditation of Laboratory Animal Care guidelines (11).

We studied surfactant metabolism in eight baboons (GA 124-127 d; full term at $185 \mathrm{~d}$ ) using stable isotopes and radioactive isotopes with surfactant treatment at different times over a 14-d period of ventilation (Fig. 1). The baboons received unlabeled surfactant at birth $[100 \mathrm{mg} / \mathrm{kg}$ Survanta (beractant), Abbott Laboratories, Abbott Park, IL, U.S.A.]. At 120 h (d 5), they received a tracer dose of $5 \mathrm{mg} / \mathrm{kg}(6.8 \mu \mathrm{mol} / \mathrm{kg})$ deuterium (stable isotope) labeled DPPC $\left({ }^{2} \mathrm{H}\right.$-DPPC, where three deuterium labels are present in the palmitoyl-groups) (L-3phosphatidylcholine dipalmitoyl-D6, Doosan Serdary Research Laboratories, NJ, U.S.A.) intratracheally. The ${ }^{2} \mathrm{H}$-DPPC was used to measure the disappearance of labeled PC palmitate from the tracheal aspirates and to calculate surfactant pool size. Day 5 was chosen because a 3-d interval is needed to reliably calculate surfactant half-life and pool size. At $192 \mathrm{~h}(\mathrm{~d}$ 8), these eight baboons received a treatment dose of $100 \mathrm{mg} / \mathrm{kg}(68$ $\mu \mathrm{mol}$ sat $\mathrm{PC} / \mathrm{kg}$ ) Survanta labeled with radioactive $\left[{ }^{14} \mathrm{C}\right] \mathrm{cho}-$ line-labeled DPPC (5 $\mu \mathrm{Ci}{ }^{14} \mathrm{C}$-DPPC/kg birth weight). A 6-d interval from $\mathrm{d} 8$ to $\mathrm{d} 14$ was chosen to compare the surfactant half-life and pool size with our previous data (11). In that study, we measured the surfactant metabolism in the first $6 \mathrm{~d}$ of life. Over the interval from birth to $\mathrm{d} 6$, most of the PC in the surfactant treatment given at birth was degraded. Tracheal aspirates were obtained every $12 \mathrm{~h}$ for $14 \mathrm{~d}$ as described before (11). At $336 \mathrm{~h}$ (d 14), the animals were killed with pentobarbital. Alveolar wash and lung homogenates were retrieved as described before (11).

Analytical procedures. The tracheal aspirates, alveolar washes, and lung homogenates were processed as described before (16). The PC fraction of the tracheal aspirates was isolated by thin-layer chromatography and derivatives of PC palmitate were formed during incubation with $0.015 \mathrm{~mL} \mathrm{~N}$ methyl-N-(tert-butyldimethylsilyl)-trifluoroacetamide (MTBSTFA, Pierce, Onmilabo, Breda, The Netherlands) and 0.015 $\mathrm{mL}$ pyridine, to measure ${ }^{2} \mathrm{H}$-enrichment. Analysis of radioactive isotopes in tracheal aspirates, alveolar washes, and lung homogenates were performed as described before (11). Fatty acid composition of surfactant PC in tracheal aspirates was measured by gas chromatography (5890 series II, HewlettPackard, Amstelveen, The Netherlands (17).

Determination of enrichment of stable isotope. The ${ }^{2} \mathrm{H}$ enrichment of surfactant PC-palmitate was measured with a Carlo Erba GC8000 gas chromatograph coupled to a Fisons MD-800 mass spectrometer (Interscience BV, Breda, The Netherlands). One microliter of the derivative was injected on a fused silica capillary column of $25 \mathrm{~m} \times 0.22 \mathrm{~mm}$, coated with $0.11 \mathrm{~m}$ HT-5 (SGE, Victoria, Australia). The enrichment was expressed as mol percent excess (MPE), which represents the molar percent of the labeled molecule $(\mathrm{m}+3$ palmitate),

\section{$100 \mathrm{mg} / \mathrm{kg}$ Survanta ${ }^{\circledR}$}

$68 \mu \mathrm{mol}$ sat $\mathrm{PC} / \mathrm{kg}$

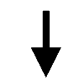

${ }^{2} \mathrm{H}$-DPPC

$6.8 \mu \mathrm{mol}$ sat PC/kg

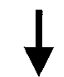

Birth
${ }^{14} \mathrm{C}$-DPPC Survanta ${ }^{\circledR}$ $68 \mu \mathrm{mol}$ sat PC/kg

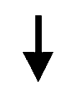

\section{Autopsy: Lung surfactant sat $P C$ pool}

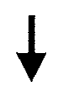

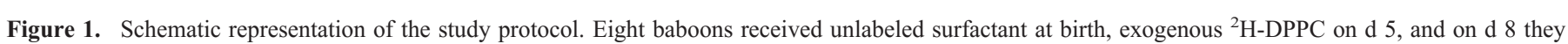

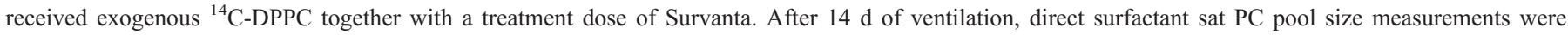
performed at autopsy. 
corrected for baseline enrichment (before isotope infusion) (18).

Calculations. Calculations were performed as described previously $(13,14)$. As palmitic acid is by far the most abundant fatty acid in surfactant PC, calculations were performed for palmitic acid only.

The half-life of ${ }^{2} \mathrm{H}$-DPPC and ${ }^{14} \mathrm{C}$-DPPC was calculated by exponential curve fitting of the final monoexponential part (y $=\mathrm{a}^{*} \mathrm{e}^{-\mathrm{kt}}$ ) of the downslope of the curve of ${ }^{2} \mathrm{H}$-enrichment and specific activity of ${ }^{14} \mathrm{C}$ versus time, respectively $[\mathrm{t} 1 / 2=\ln$ $(2) / k]$.

The apparent lung surfactant pool size was calculated by using the linear regression line representing the decay of the log-transformed ${ }^{2} \mathrm{H}$-enrichment over time. Extrapolation back to the time of administration $(t=120 \mathrm{~h}$ ) represents the ${ }^{2} \mathrm{H}$-enrichment at $\mathrm{t}=120$, from which we calculate the dilution of the tracer. The endogenous apparent pool size was calculated by multiplying the amount of exogenous DPPC with the dilution factor. The endogenous apparent pool size was corrected for the amount of exogenous ${ }^{2} \mathrm{H}-\mathrm{DPPC}$ administered, and expressed as micromoles per kilogram sat $\mathrm{PC}$ by using the fatty acid composition of PC obtained by GC.

Data analysis. Data are presented as mean \pm SEM. Differences between groups were analyzed by one-way ANOVA. Significance was accepted at $p<0.05$.

\section{RESULTS}

We studied eight baboons with a mean birth weight of 386 $\pm 11 \mathrm{~g}$ (four females, four males).

On $\mathrm{d} 5$, the baboons received a trace dose of ${ }^{2} \mathrm{H}$-labeled DPPC $(6.8 \mu \mathrm{mol} / \mathrm{kg})$. The values of the ${ }^{2} \mathrm{H}$-enrichment of PC palmitate in sequential tracheal aspirates versus time were used to calculate a half-life of $28 \pm 4 \mathrm{~h}$ (Fig. $2 B$, Table 1). The half-life was calculated from the final monoexponential part of the decrease in ${ }^{2} \mathrm{H}$-enrichment in each baboon.

On $\mathrm{d} 8$, the baboons received a therapeutic dose of radioactive surfactant (100 mg/kg Survanta, $68 \mu \mathrm{mol} \mathrm{sat} \mathrm{PC/kg).} \mathrm{The}$ half-life, calculated by exponential curve fitting of the final monoexponential part of the downslope of the curve of the specific activity of ${ }^{14} \mathrm{C}$-DPPC in airway samples versus time curve, was $35 \pm 4 \mathrm{~h}$ (Fig. $2 A$, Table 1 ).

We compared the results of these eight baboons with our previous data for surfactant metabolism in similar premature baboons that were ventilated for $6 \mathrm{~d}(11,16)$. The previous studies in very premature baboons (GA $125 \pm 2$ d) were performed by the same investigators, using the same pre- and postnatal care. The half-life of ${ }^{14} \mathrm{C}$-DPPC given on $\mathrm{d} 0$ in the previous study is shown in Table 1 . The results show similar half-lives on $\mathrm{d} 0,5$, and 8 after birth.

The apparent lung sat PC pool size on d 5 was $129 \pm 14$ $\mu \mathrm{mol} / \mathrm{kg}$ (Table 1). The pool size was calculated from the monoexponential decrease in ${ }^{2} \mathrm{H}$-enrichment, by using the linear regression line representing the decay of the logtransformed ${ }^{2} \mathrm{H}$-enrichment over time. On d 14, the pool size of sat PC measured for the total lung was $123 \pm 11 \mu \mathrm{mol} / \mathrm{kg}$ (Table 1). Total lung pool size on $\mathrm{d} 0$ and 6 from previous experiments are shown for comparison (11). There was no
A

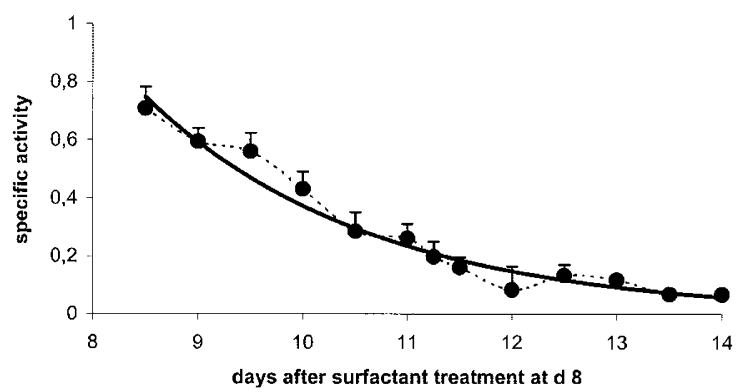

B

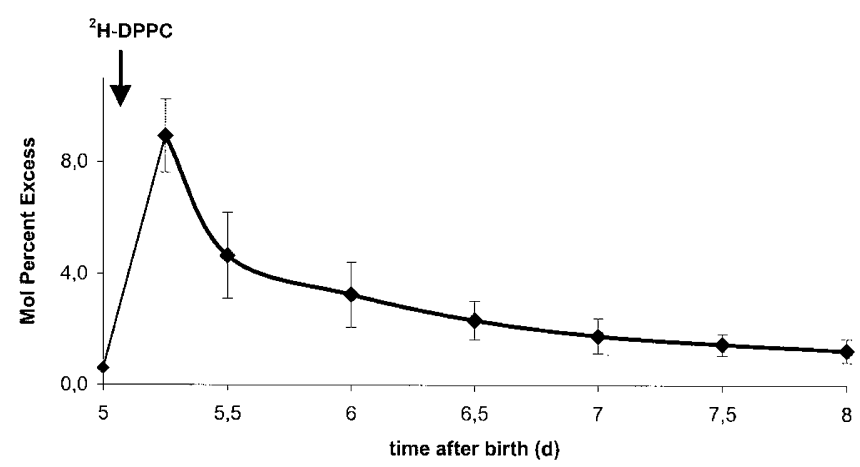

Figure 2. Decay of the label in tracheal aspirates after endotracheal administration of labeled DPPC. $(A)$ Specific activities of sat PC from tracheal aspirates after treatment of baboons with ${ }^{14} \mathrm{C}$-DPPC labeled $100 \mathrm{mg} / \mathrm{kg}$ Survanta on $\mathrm{d} 8$. Specific activities as $\mathrm{CPM} / \mu \mathrm{mol}$ sat $\mathrm{PC}$ were normalized to the specific activity of the surfactant used to treat the preterm baboons. $(B)$ Mean $\pm S E M{ }^{2} \mathrm{H}$-enrichment of surfactant PC-associated palmitate in sequential tracheal aspirates of eight baboons (125 GA) after ${ }^{2} \mathrm{H}-\mathrm{DPPC}$ (stable isotope) administration at $\mathrm{d} 5(\mathrm{t}=120 \mathrm{~h})$.

significant difference between pool sizes on d 5, 6, and 14 (one-way ANOVA, $p=0.065$ ).

\section{DISCUSSION}

BPD was initially described as severe injury of the preterm lung resulting from mechanical ventilation and oxygen exposure (19). With the introduction of surfactant therapy and prenatal corticosteroids, BPD now primarily develops in very preterm infants weighing $<1 \mathrm{~kg}$, without severe RDS. This new BPD may be primarily caused by an arrest of lung development (20). We report here surfactant metabolism during the early phase of BPD in very premature baboons. Halflife and apparent lung sat PC pool size were calculated after endotracheal instillation of a tracer dose of deuterium-labeled DPPC on d 5 after birth. On d 8 of life, half-life was measured after endotracheal radiolabeled DPPC together with a treatment dose of surfactant, and pool size measurements from whole lung were made on $\mathrm{d} 14$. We show that although the baboons recover from RDS and develop the early phase of BPD, surfactant sat PC half-life and surfactant sat PC pool size do not change. It remains presently unclear whether the surfactant metabolism plays a role in the pathogenesis of BPD.

Most studies of surfactant kinetics have been performed over a short time course. In the present study, we were able to 
Table 1. Surfactant half-lives and sat PC pool sizes

\begin{tabular}{lccccc}
\hline & $\begin{array}{c}\text { D0* } \\
\end{array}$ & $\begin{array}{c}\text { D5 } \\
{ }^{14} \text { C-DPPC/autopsy }\end{array}$ & $\begin{array}{c}\text { D6* } \\
\text { autopsy }\end{array}$ & $\begin{array}{c}\text { D8 } \\
{ }^{14} \text { C-DPPC }\end{array}$ & $\begin{array}{c}\text { D14 } \\
\text { autopsy }\end{array}$ \\
\hline Half-life $(\mathrm{h})$ & 30 & $28 \pm 4$ & - & $35 \pm 4$ & - \\
Pool size $(\mu \mathrm{mol} / \mathrm{kg}$ sat PC) & 30 & $129 \pm 14$ & $166 \pm 11$ & - \\
\hline
\end{tabular}

Half-life and sat PC pool size expressed as mean \pm SEM. On d 5, the baboons received ${ }^{2} \mathrm{H}$-DPPC (stable isotope) endotracheally, on $\mathrm{d} 8$ they received ${ }^{14} \mathrm{C}$-DPPC (radioactive) with Survanta $(100 \mathrm{mg} / \mathrm{kg}$ ) endotracheally, and on $\mathrm{d} 14$ the baboons were killed.

* The results are compared with results reported previously (11).

evaluate surfactant metabolism during the first 2 wk of life in the same animal. In our previous study, we measured surfactant synthesis in the acute phase of RDS, and surfactant half-life and pool size were studied after treatment with surfactant at birth. By using a 14-d ventilated preterm baboon model, which shows abnormal alveolar development and injury similar to that found in humans (21), we were now able to measure surfactant kinetics during the development of BPD, more specifically on d 5 , and after surfactant treatment on d 8 . Our measurements in the preterm baboon are summarized in Figure 3. We measured a low sat PC pool size at birth, which was increased at d 6 after surfactant treatment. As $84 \%$ of the ${ }^{14} \mathrm{C}$-DPPC given at birth was degraded by d 6 (11), the increase of the total sat PC pool size resulted from endogenous synthesis of surfactant. In the second week of life, the pattern of surfactant metabolism was similar: about $90 \%$ of the ${ }^{14} \mathrm{C}$ DPPC administered at $\mathrm{d} 8$ was degraded by d 14 (22), whereas the total lung sat PC pool size did not change significantly.

Sat PC pool size on d 5, measured with stable isotopes, was $129 \mu \mathrm{mol} / \mathrm{kg}$ and was comparable to the total lung pool size measured at autopsy on d $14(123 \mu \mathrm{mol} / \mathrm{kg})$ in the same animal. The trend of a larger sat PC pool size at autopsy on d 6 in the previous study $(166 \mu \mathrm{mol} / \mathrm{kg})(11)$ compared with the pool size on d 5 in the current study, may be explained by measurements in different animals. It is also unclear to what extent an abnormal surfactant metabolism influences the measurements. In the previous study, we found very high tissue pools, but low alveolar pool sizes of surfactant, caused by a low secretion of de novo synthesized sat PC into the alveolar space. No other studies have investigated the evolution of surfactant pool sizes in premature animals during a longer period. A study in term rats found a progressive decrease in total lung sat PC pool sizes corrected for weight during the first $100 \mathrm{~d}$ after birth (from $\sim 125 \mu \mathrm{mol} / \mathrm{sat} \mathrm{PC} / \mathrm{kg}$ to $\sim 5 \mu \mathrm{mol} / \mathrm{sat}$ $\mathrm{PC} / \mathrm{kg})(23)$.

Jackson et al. (24) measured a total lung pool size of sat PC of $\sim 45 \mu \mathrm{mol} / \mathrm{kg}$ in preterm monkeys with RDS at birth. However, these monkeys were not as premature as the baboons in the present study $(83 \%$ versus $68 \%$ of the term gestational age) and they did not receive exogenous surfactant. Preterm lambs delivered at $132 \mathrm{~d}$ gestational age had total lung sat PC pool sizes of $\sim 60 \mu \mathrm{mol} / \mathrm{kg}$ without surfactant treatment (25) and $\sim 80 \mu \mathrm{mol} / \mathrm{kg}$ sat PC when treated with surfactant (26). In preterm neonates, using stable isotopes, we previously measured an apparent sat PC pool size of $\sim 8 \mu \mathrm{mol} / \mathrm{kg}$ and $\sim 22$ $\mu \mathrm{mol} / \mathrm{kg}$ before and after surfactant therapy, respectively (14). Hallman et al. (27) showed an apparent pool size of $\sim 12$ $\mu \mathrm{mol} / \mathrm{kg}$ in human preterm neonates with RDS. They used PG

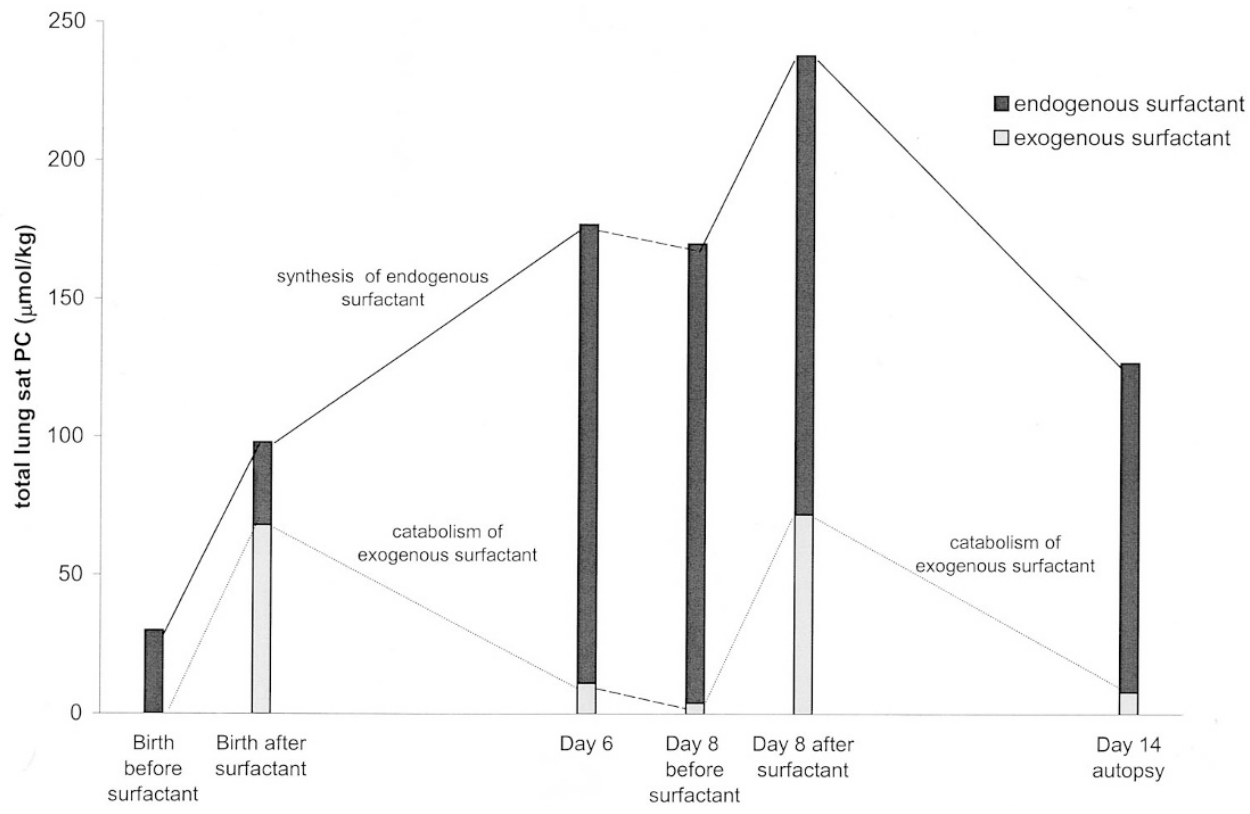

Figure 3. An overview of the surfactant metabolism during the first $2 \mathrm{wk}$ of life in the very premature ventilated baboon. At birth the baboons received 68 $\mu \mathrm{mol} / \mathrm{kg}$ sat PC Survanta, from which $84 \%$ was degraded at d 6 [results reported previously (11)]. Pool size at d 6 was $166 \mu \mathrm{mol} / \mathrm{kg}$ sat PC, which indicates an increase of pool size by endogenous surfactant synthesis. In the second week of life during the early development of BPD, the endogenous surfactant pool size remains fairly constant and catabolism is similar to that in the first week after a dose of $68 \mu \mathrm{mol} / \mathrm{kg}$ sat PC Survanta. 
as label to measure surfactant pool size. With the same method, Griese et al. (28) calculated an apparent pool size of $\sim 13$ $\mu \mathrm{mol} / \mathrm{kg}$ sat PC in preterm neonates with RDS. However, the pool size measurements in humans were made with a tracer together with one or more therapeutic doses of surfactant, whereas in the present study only a trace dose of surfactant was used on $\mathrm{d} 5$. The pool sizes measured in the human studies probably represent the alveolar pool sizes. Their apparent pool size was comparable with the alveolar pool size found in other studies $(\sim 20 \mu \mathrm{mol} / \mathrm{kg})(15)$. In the current study, the pool size measured with stable isotopes likely represents the total lung pool size as the small amount of tracer is quickly taken up by the lung cells in contrast to the large treatment doses.

The half-life of DPPC over the interval from $\mathrm{d} 5$ to $\mathrm{d} 8$, using stable isotopes, was $28 \pm 4 \mathrm{~h}$, which was similar to the half-life measured with radioactive DPPC from d 8 onward. Similar results were found at $\mathrm{d} 0$, using radioactive DPPC, in our previous study (11). Thus, the half-life of surfactant did not change during the first 2 wk of life in the very premature baboon. The same half-life of $35 \mathrm{~h}$ was found in preterm lambs using PG as tracer in alveolar washes (29). In one study in term newborn lambs, endotracheally injected ${ }^{3} \mathrm{H}-\mathrm{PC}$ had a very long half-life of $6 \mathrm{~d}$ (30). Possibly, variations of half-lives are due to differences in maturity. In premature infants treated with amniotic fluid-derived surfactant containing PG, the half-life was $30 \mathrm{~h}$ (27). In another study in premature infants using PG and $\mathrm{Sp}$ as markers, half-life of PG was $43 \mathrm{~h}$ and $105 \mathrm{~h}$ after treatment with Alveofact and Survanta, respectively, and the half-life of Sp was $97 \mathrm{~h}$ after treatment with Survanta (28). The differences in half-lives could be explained by the different composition of the two surfactants and the different doses given. Comparable results were found in human premature neonates using stable isotopes (14). Preterm infants received two doses of surfactant labeled with ${ }^{13} \mathrm{C}$-atoms, $5 \mathrm{~h}$ and $32 \mathrm{~h}$ after birth, respectively. The calculated half-life was $34 \mathrm{~h}$ and $17 \mathrm{~h}$, respectively. All these studies in human neonates calculated half-life from the disappearance of the label (PG, Sp, and ${ }^{13} \mathrm{C}$ ) from tracheal aspirates, as in the current study. The half-life of a trace amount of labeled DPPC (d 5) in the present study was not influenced by the administration of treatment doses of surfactant $(100 \mathrm{mg} / \mathrm{kg})(\mathrm{d} 8)$, which is in agreement with Hallman et al. (27), and with our previous results (31). However, in mice the half-life for ${ }^{3} \mathrm{H}$-DPPC in total lung increased $\sim 2$-fold after the instillation of $45 \mu \mathrm{mol} / \mathrm{kg}$ sat PC compared with a trace dose (32). Nevertheless, further increase of the dose had no effect on the half-life.

As a secondary goal, we compared the method of DPPC half-life and sat PC pool size measurements using stable isotopes with that of radioactive isotopes and surfactant pool size measurements at autopsy in very premature ventilated baboons. The results obtained with the use of stable isotopes were comparable to the results obtained with radioactive tracers and tissue measurements of pool size. Estimation of surfactant half-life and pool size by the isotope dilution method is based on several assumptions. The distribution of the exogenous surfactant and the endogenous surfactant has to be similar, the phospholipid composition in the various surfactant compartments has to be uniform, the surfactant system has to be pulse labeled, there should be no endogenous synthesis of the label, and the pool size after exogenous surfactant has to be constant. It is reasonable to assume that most of the assumptions have been fulfilled as has been extensively discussed by Hallman et al. (27)and by Torresin et al. (14).

In conclusion, The metabolism of surfactant PC did not change during the recovery from RDS and the development of BPD. Very preterm baboons have low sat PC pool size at birth. Treatment with surfactant increased instantaneously the total lung sat PC pool size, which was kept relatively constant by endogenous surfactant synthesis. Half-lives of surfactant PC did not change during the first 2 wk of life. We also showed that stable isotopes are a valid tool for studying surfactant metabolism in vivo. This method can be easily applied to human neonates, which will enable us to better understand the role of surfactant in different neonatal lung diseases.

Acknowledgments. The authors thank Wim van den Berg (Internal Medicine II, Erasmus University Rotterdam, The Netherlands), Jan Erik Bunt (Department of Pediatrics, Sophia Children's Hospital Rotterdam, The Netherlands) for excellent support and technical advice, Esther Wit and Lars de Zeeuw (medical students, Erasmus University, Rotterdam, The Netherlands) for technical assistance, and the BPD Resource Center at the Southwest Foundation for Biomedical Research.

\section{REFERENCES}

1. Jobe AH 1993 Pulmonary surfactant therapy. N Engl J Med 328:861-868

2. Jobe AH 1988 The role of surfactant in neonatal adaptation. Semin Perinatol 12:113-123

3. Jobe AH 1988 Metabolism of endogenous surfactant and exogenous surfactants for replacement therapy. Semin Perinatol 12:231-244

4. Jobe AH, Ikegami M 1998 Surfactant and acute lung injury. Proc Assoc Am Physicians 110:489-495

5. Bland RD, Coalson JJ 2000 Chronic Lung Disease in Early Infancy. Marcel Dekker, New York

6. Bancalari E, del Moral T 2001 Bronchopulmonary dysplasia and surfactant. Bio Neonate 80(suppl 1):7-13

7. Clement A, Masliah J, Housset B, Just J, Garcia J, Grimfeld A, Tournier G 1987 Decreased phosphatidyl choline content in bronchoalveolar lavage fluids of children with bronchopulmonary dysplasia: a preliminary investigation. Pediatr Pulmonol 3:67-70

8. Hallman M, Merritt TA, Akino T, Bry K 1991 Surfactant protein a, phosphatidylcholine, and surfactant inhibitors in epithelial lining fluid. Correlation with surface activity, severity of respiratory distress syndrome, and outcome in small premature infants. Am Rev Respir Dis 144:1376-1384

9. Pandit PB, Dunn MS, Kelly EN, Perlman M 1995 Surfactant replacement in neonates with early chronic lung disease. Pediatrics 95:851-854

10. Coalson JJ, Seidner S, deLemos RA 2000 Animal models of chronic lung injury. In: Bland RD, Coalson JJ (eds) Chronic Lung Disease in Early Infancy. Marcel Dekker, New York, pp 927-956

11. Seidner SR, Jobe AH, Coalson JJ, Ikegami M 1998 Abnormal surfactant metabolism and function in preterm ventilated baboons. Am J Respir Crit Care Med 158:19821989

12. Awasthi S, Coalson JJ, Crouch E, Yang F, King RJ 1999 Surfactant proteins a and d in premature baboons with chronic lung injury (bronchopulmonary dysplasia). Evidence for an inhibition of secretion. Am J Respir Crit Care Med 160:942-949

13. Bunt JE, Zimmermann LJI, Wattimena JLD, Beek v RH, Sauer PJJ, Carnielli VP 1998 Endogenous surfactant turnover in preterm infants measured with stable isotopes. Am J Respir Crit Care Med 157:810-814

14. Torresin M, Zimmermann LJ, Cogo PE, Cavicchioli P, Badon T, Giordano G, Zacchello F, Sauer PJ, Carnielli VP 2000 Exogenous surfactant kinetics in infant respiratory distress syndrome: a novel method with stable isotopes. Am J Respir Crit Care Med 161:1584-1589

15. Adams FH, Fujiwara T, Emmanouilides GC, Raiha N 1970 Lung phospholipids of human fetuses and infants with and without hyaline membrane disease. J Pediatr 77:833-841

16. Bunt JE, Carnielli VP, Seidner SR, Ikegami M, Darcos Wattimena JL, Sauer PJ, Jobe $\mathrm{AH}$, Zimmermann LJ 1999 Metabolism of endogenous surfactant in premature baboons and effect of prenatal corticosteroids. Am J Respir Crit Care Med 160:14811485 
17. IJsselstijn H, Zimmermann LJI, Bunt JEH, de Jongste JC, Tibboel D 1998 Prospective evaluation of surfactant composition in bronchoalveolar lavage fluid of infants with congenital diaphragmatic hernia and of age-matched controls. Crit Care Med 26:573-580

18. Wolfe RR 1992 Radioactive and Stable Isotope Tracers in Biomedicine. Principles and Practice of Kinetic Analysis. Wiley-Liss, New York

19. Northway Jr WH, Rosan RC, Porter DY 1967 Pulmonary disease following respiratory therapy of hyaline-membrane disease: bronchopulmonary dysplasia. N Engl J Med 276:357-368

20. Jobe AJ 1999 The new BPD: An arrest of lung development. Pediatr Res 46:641-643

21. Coalson JJ, Winter VT, Siler-Khodr T, Yoder BA 1999 Neonatal chronic lung disease in extremely immature baboons. Am J Respir Crit Care Med 160:1333-1346

22. Seidner SR, Jobe AH, Ikegami M 2000 Surfactant metabolism following late surfactant treatment doses during BPD development in preterm baboons. Pediatr Res 47:376A(abstr)

23. Ohashi T, Pinkerton K, Ikegami M, Jobe AH 1994 Changes in alveolar surface area, surfactant protein a, and saturated phosphatidylcholine with postnatal rat lung growth. Pediatr Res 35:685-689

24. Jackson JC, Palmer S, Truog WE, Standaert TA, Murphy JH, Hodson WA 1986 Surfactant quantity and composition during recovery from hyaline membrane disease. Pediatr Res 20:1243-1247

25. Michna J, Jobe AH, Ikegami M 1999 Positive end-expiratory pressure preserve surfactant function in preterm lambs. Am J Respir Crit Care Med 160:634-639
26. Jobe AH, Newnham JP, Willet KE, Moss TJ, Gore Ervin M, Padbury JF, Sly P, Ikegami M 2000 Endotoxin-induced lung maturation in preterm lambs is not mediated by cortisol. Am J Respir Crit Care Med 162:1656-1661

27. Hallman M, Merritt TA, Pohjavuori M, Gluck L 1986 Effect of surfactant substitution on lung effluent phospholipids in respiratory distress syndrome: evaluation of surfactant phospholipid turnover, pool size, and the relationship to severity of respiratory failure. Pediatr Res 20:1228-1235

28. Griese M, Dietrich P, Reinhardt D 1995 Pharmacokinetics of bovine surfactant in neonatal respiratory distress syndrome. Am J Respir Crit Care Med 152:1050-1054

29. Ikegami M, Jobe AH, Yamada T, Priestly A, Ruffini L, Rider E, Seidner SR 1989 Surfactant metabolism in surfactant-treated preterm ventilated lambs. J Appl Physiol 67:429-437

30. Glatz T, Ikegami M, Jobe AH 1982 Metabolism of exogenously administered natural surfactant in the newborn lamb. Pediatr Res 16:711-715

31. Bunt JE, Carnielli VP, Janssen DJ, Wattimena JL, Hop WC, Sauer PJ, Zimmermann LJ 2000 Treatment with exogenous surfactant stimulates endogenous surfactant synthesis in premature infants with respiratory distress syndrome. Crit Care Med 28:3383-3388

32. Kramer BW, Ikegami M, Jobe AH; 2000 Surfactant phospholipid catabolic rate is pool size dependent in mice. Am J Physiol Lung Cell Mol Physiol 279:L842L848 